\title{
David Buckingham: a Educação Midiática não deve apenas lidar com o mundo digital, mas sim exigir algo diferente
}

\section{Douglas Calixto}

Jornalista formado pela Unesp, é mestre e doutorando em Ciências da Comunicação pela ECA-USP. Integra o grupo de pesquisa Mediações Educomunicativas (MECOM), da ECA-USP. Desenvolve pesquisa com memes na internet, podcast e outras linguagens na educomunicação. E-mail:dcalixto@usp.br

Tatiana Garcia Luz-Carvalho Jornalista formada pela Faculdade Cásper Líbero e licenciada em Educomunicação pela ECA-USP. É mestranda em Ciências da Comunicação pela mesma universidade. Integra o grupo de pesquisa MECOM, da ECA-USP.

E-mail: luzcarvalho.tatiana@usp.com

\section{Adilson Citelli}

Professor titular no Departamento de Comunicações e Artes e do Programa de Pós-Graduação em Ciências da Comunicação da ECA-USP. É coordenador do Grupo de Pesquisa MECOM e bolsista $1 B$ do CNPq. Autor de inúmeros livros e artigos acadêmicos.

E-mail: citelli@uol.com.br

Resumo: David Buckingham concedeu entrevista exclusiva à Revista Comunicação \& Educação. Realizado remotamente, o diálogo tem o intuito de elucidar aspectos práticos e teóricos que marcam a obra do autor. Buckingham analisa questões da interface comunicação e educação, as referências teóricas compartilhadas com os estudos culturais e, sobretudo, o entendimento de que é necessário superar o viés instrumental da mídia em favor de uma compreensão abrangente sobre o capitalismo digital. $\mathrm{Na}$ entrevista, o pesquisador responde questões relacionadas à formação docente no campo das tecnologias digitais, ao desenvolvimento de estratégias
Abstract: British researcher David Buckingham gave an interview to Revista Comunicação \& Educação, via a virtual conference, recently in Brazil. Buckingham analyzes issues of the communication and education interface, the theoretical references shared with cultural studies, and primarily, the understanding that it is necessary to overcome the instrumental bias of the media in favor of a comprehensive understanding of digital capitalism. In the interview, Buckingham answers questions related to teacher training in the field of digital technologies, the development of pedagogical strategies to deal with digital 
comunicação \& educação • Ano XXV • número 2 • jul/dez 2020

pedagógicas para lidar com o capitalismo digital no âmbito escolar e, especialmente, ao conceito de educação midiática.

Palavras-chave: educação midiática; infâncias; juventudes; capitalismo digital; tecnologias. capitalism at school and, above all, the concept of media education.

Keywords: media education; childhood; youth; digital capitalism; technologies.

Comunicação Ẽ Educação entrevista David Buckingham, professor emérito da Universidade de Loughborough e professor visitante do King's College e da Universidade de Londres, no Reino Unido. Ele também dirigiu o Centre for the Study of Children, Youth and Media da Universidade de Londres. O intelectual britânico é internacionalmente conhecido pelo trabalho com infâncias, juventudes, tecnologias e Educação Midiática, sendo autor e coautor de mais de 25 livros nessas áreas. Entre os trabalhos mais recentes está o livro The media education manifesto, no qual o pesquisador propõe uma nova perspectiva analítica diante dos desafios contemporâneos: "Compreender a mídia hoje requer o reconhecimento da complexidade das formas modernas do 'capitalismo digital'. E se realmente queremos que os cidadãos sejam alfabetizados em mídia, precisamos de programas abrangentes, sistemáticos e sustentáveis de educação para a mídia como um direito básico para todos os jovens", analisa.

Em 14 de setembro, David Buckingham apresentou uma conferência virtual promovida pelo Colégio Santa Cruz, em São Paulo. Na ocasião, fizemos o contato para a posterior realização desta entrevista. No blog do professor, também é possível encontrar diversos artigos e publicações.

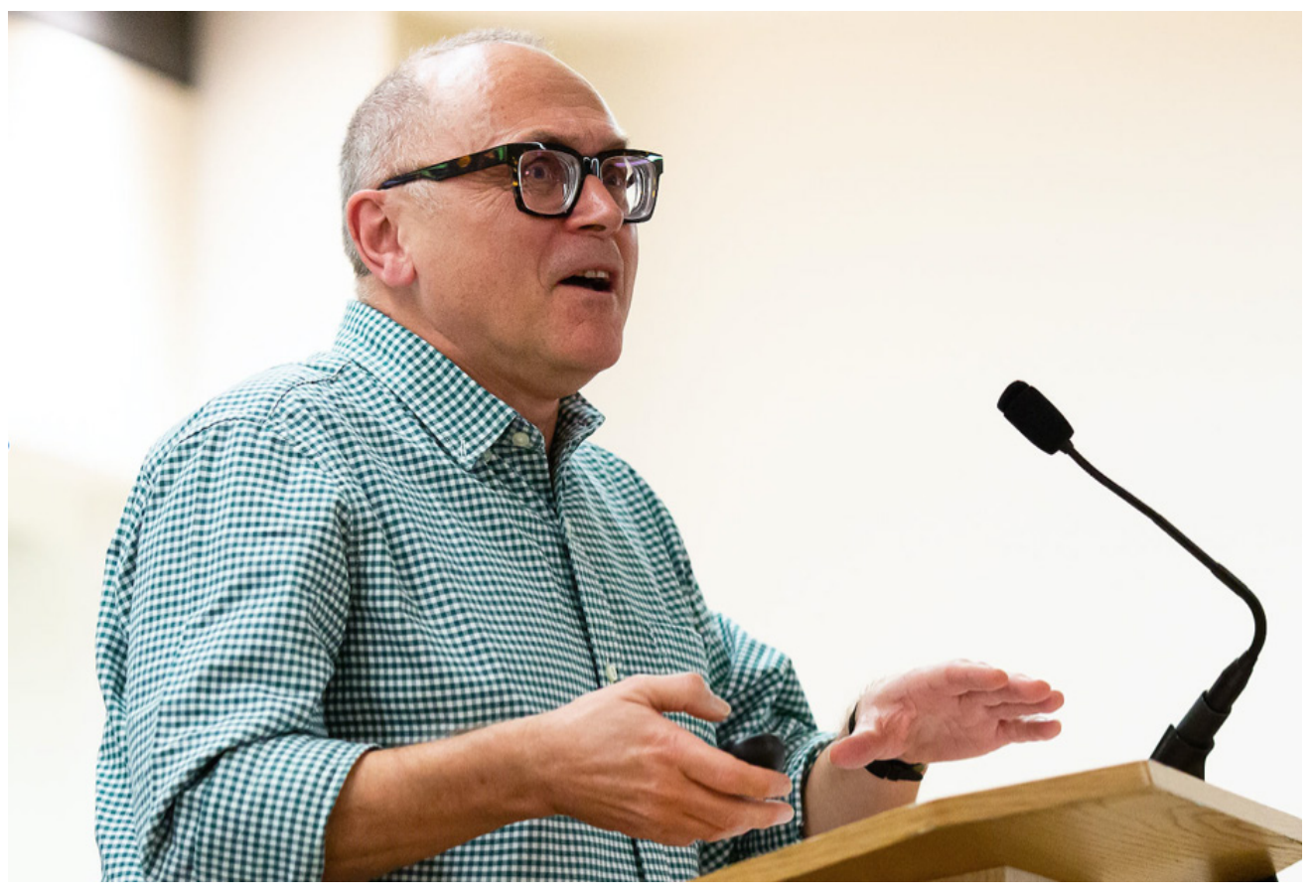


Comunicação Ẽ Educação: Um ponto fundamental em sua obra é a reflexão sobre as mídias digitais não apenas como tecnologias, mas também como cultura. Na América Latina, esta perspectiva aparece em autores como Martín-Barbero, Mario Kaplún e Orozco Gómez. Qual caminho teórico o senhor percorreu para chegar a esse entendimento sobre a mídia e o que ele representa para as práticas de Educação Midiática?

David Buckingham: Talvez devêssemos começar do início, perguntando: para que serve a educação? Eu penso que a maioria das pessoas concordaria que o objetivo da educação é preparar as crianças para a vida adulta - ajudá-las a entender o mundo no qual estão crescendo e a se tornarem participantes ativas (ou cidadãs) nesse mundo. Isso implica no fato de que a educação precisa estar orientada para o futuro - embora, claro, tal constatação não signifique que ela não possa ou deva aprender com o passado.

Ao longo do século XX - e agora no XXI -, o mundo se tornou crescentemente saturado com as mídias de vários tipos. Há tempos a mídia vem desempenhando papel central na economia, na política, na vida pública, nas artes. E, agora, as nossas próprias relações pessoais com amigos e familiares passaram a ser influenciadas pelos meios digitais. Quase tudo é mediado de alguma forma. Se queremos preparar as crianças para este mundo, precisamos constantemente ensiná-las sobre a mídia.

Claro, as crianças entendem bastante sobre a cultura da mídia simplesmente experimentando-a e participando dela. Elas desenvolvem formas de criatividade e habilidades de comunicação, aprendendo a "ler" e "escrever", discernir e julgar nessas mídias. As crianças trazem para a sala de aula amplas fontes de conhecimento e entendimento que derivam das experiências fora da escola, e esse é o conhecimento que os professores geralmente tendem a subestimar ou ignorar.

No entanto também há um perigo em romantizarmos os jovens como "nativos digitais", que aparentemente já sabem tudo. Quando se trata das mídias, há muito que as crianças provavelmente não aprenderão simplesmente por meio da experiência. Elas precisam entender como tais mídias funcionam, não apenas tecnologicamente, mas também como formas de linguagem ou produtoras de sentidos; elas precisam entender as dimensões políticas, sociais e econômicas das mídias; e elas necessitam promover julgamentos mais críticos e sistemáticos sobre as mídias que estão usando e consumindo. Essas são coisas que elas deveriam aprender na escola.

Assim, é necessário haver um encontro entre a cultura da escola - e os tipos de conhecimento por ela valorizados - e as culturas que as crianças experienciam fora da escola. Ainda, a educação também deve lhes fornecer experiências, conhecimentos e competências que, de outra forma, não poderiam manifestar em espaços não escolares.

As unidades educativas formais sempre trabalharam com mídias dos mais variados tipos: filmes, televisão, computadores, mas também com livros e outros veículos impressos. Mas, no ensino, tendemos a usar as mídias como ferramentas - ou, como costumamos chamar, "apoio/auxílio audiovisual”. Geralmente 
as usamos para trazer aspectos do mundo externo para a sala de aula, mas frequentemente deixamos de formular questões fundamentais sobre como essas mídias representam o mundo e como e por que elas foram produzidas.

Enquanto isso, muitas vezes, existe uma grande divisão entre como os jovens se envolvem com as mídias fora da escola e o que acontece na sala de aula. Fora da escola, eles estão usando as mídias digitais não apenas para o aprendizado formal, mas também para entretenimento, prazer e comunicação. Já na escola, essas mídias geralmente são usadas meramente para recuperar informações, para exercícios de repetição e memorização², e para formas mecânicas de instrução. As crianças podem aprender a gerenciar arquivos, PowerPoint e programação básica, mas raramente se envolvem com as ricas formas de imagens visuais e em movimento que encontram todos os dias fora da escola.

Portanto, ao usar a ideia de "cultura digital", estou argumentando que precisamos fazer a ponte entre as experiências cotidianas e o conhecimento escolar. Em vez de olhar para as mídias meramente como um conjunto de dispositivos tecnológicos, precisamos nos envolver com os conhecimentos e as habilidades que as crianças desenvolvem ao usar as mídias fora da escola, e construir as experiências pedagógicas a partir dessas tecnologias.

$C \mathcal{E} E$ : Professor, está claro esse entendimento sobre o uso instrumental da mídia. No entanto o senhor poderia expandir a questão teórica que envolve a Educação Midiática? Qual é a influência, por exemplo, dos estudos culturais no referencial teórico que o senhor trabalha?

DB: Vejo que não respondi bem à última pergunta sobre meu "caminho teórico". Talvez seja porque, para mim, educação não é muito sobre desenvolver uma teoria abstrata e aplicá-la: é mais sobre a práxis, sobre uma relação dinâmica entre teoria e prática.

Mas, se os educadores midiáticos do Reino Unido têm um "caminho teórico", então os estudos culturais são com certeza uma parte vital disso. Infelizmente, os estudos culturais se tornaram muitas coisas diferentes para muitas pessoas, e hoje é quase impossível defini-los. Eu olho para a tradição que começa com o encontro entre as disciplinas de Literatura Inglesa e Sociologia, no final dos anos 1950, na Grã-Bretanha. Esse foi um período histórico muito interessante, em que é possível ver as mudanças sociais e culturais radicais que se concretizaram na década de 1960, apenas começando a aparecer, principalmente de formas bastante incertas e provisórias.

Ainda no início do trabalho dos "avôs" dos estudos culturais - como Richard Hoggart, Raymond Williams e Stuart Hall -, se reconhece envolvimento com uma definição mais ampla de cultura do que a anterior. Cultura para eles não dizia respeito apenas a um conjunto de textos aprovados, um cânone da alta literatura e das belas artes. Ao contrário, a cultura dizia respeito à experiência de vida das pessoas: não era algo exaltado e separado, mas algo embutido na vida cotidiana, algo bastante "ordinário". E, é claro, para todos esses escritores, 
classe trabalhadora, não apenas a cultura da elite. Então havia uma intenção política no cerne dos estudos culturais: era parte de um largo processo de democratização, uma "longa revolução", como Williams a chamou.

Tal perspectiva pavimentou o caminho para análises sérias da cultura popular e das mídias, embora mesmo naquele momento houvesse muitas outras influências apontando para a mesma direção. Existem algumas perguntas sérias que devemos fazer, sessenta anos depois, sobre o que se tornaram os estudos culturais nas universidades: em muitos aspectos, eles se tornaram apenas outra disciplina acadêmica, outro tipo de "tudo conforme o habitual". Mas, se olharmos para o trabalho de Raymond Williams - como tenho feito em meu blog recentemente -, verificamos uma ênfase central à educação popular democrática nas escolas. Infelizmente, gerações subsequentes dos estudiosos dos estudos culturais não se interessaram particularmente por essa dimensão educacional.

Nesse momento, você também pode ver o "referencial teórico" começando a emergir. Williams, por exemplo, foi formado como crítico literário, mas, em seus primeiros trabalhos, ele começa a desenvolver uma reflexão mais ampla de cultura - não apenas analisando textos literários, mas também explorando sistematicamente como aqueles textos eram produzidos, divulgados e lidos. A cultura passou a ser entendida como fenômeno social, econômico e político, e não apenas como questão estética: portanto encontramos estudiosos considerando, por exemplo, a economia da indústria editorial, o papel da imprensa popular, o desenvolvimento da política cultural e assim por diante. Nesse período, especialmente nas décadas de 1960 e 1970, há outras influências teóricas e métodos aparecendo, mas a natureza dinâmica e multidimensional dos estudos culturais é evidente desde esses primeiros trabalhos. E é essa abordagem que principia a encontrar caminhos nas escolas dos anos 1970.

Deve-se enfatizar que os estudos culturais, nas origens, não tratavam apenas da cultura popular: eram sobre uma gama muito mais ampla de fenômenos culturais e sobre "alta" cultura também. Uma vez que os Estudos das Mídias se estabilizaram como uma disciplina separada (nas escolas e, nas mais variadas formas, nas universidades), houve uma tendência para apartar o campo cultural. No ensino do inglês, nós olhamos para os livros, principalmente uma categoria particular de livros que são legitimados como "literatura". Nos Estudos das Mídias, nós olhamos para todo o resto: cinema, televisão, jornal, jogos de computador, internet e assim por diante. Não há uma lógica real para isso: nós deveríamos fazer as mesmas perguntas fundamentais sobre os livros, assim como procedemos sobre outras mídias. O que precisamos é de uma abordagem mais coerente e inclusiva para ensinar mais amplamente acerca da cultura e da comunicação - e esta, eu acho, é outra boa razão para retornar às origens dos estudos culturais.

CEEE: Ao tratar da Educação Midiática no Reino Unido, o senhor indica um novo paradigma, que data do final dos anos 1980 e início dos anos 1990, o 
qual teria como conceitos-chave as linguagens, representações, instituições e audiências da mídia. $O$ senhor poderia apontar brevemente a situação atual da Educação Midiática como campo de trabalho?

DB: Há muito tempo venho defendendo a Educação Midiática e temo que sempre tenha sido uma luta difícil. O status da Educação Midiática está inevitavelmente vinculado a lutas políticas mais amplas pela educação como um todo. Ao promover a Educação Midiática, temos que pensar pragmaticamente sobre o que podemos alcançar nessa situação política e o que pretendemos alcançar em um mundo ideal. E muitas vezes é uma questão de dois passos para frente e um passo para trás, embora, nos últimos dez anos, tenha parecido mais um passo para frente e dois passos para trás.

Na década de 1970, quando os Estudos de Mídia começaram a se desenvolver como disciplina distinta nas escolas secundárias, os professores tinham um grau considerável de autonomia para desenvolver seu próprio currículo, e essa autonomia tem sido subsequentemente minada. $\mathrm{O}$ modelo de "conceitos-chave" registra uma longa história, mas foi formalizado na década de 1980, em resposta a mudanças amplas no sistema de exames. Olhando para trás, as décadas de 1980 e 1990 expressam um período de progresso significativo para a Educação Midiática. Havia um novo Currículo Nacional, realmente pela primeira vez e, enquanto a Educação Midiática era apenas uma pequena parte da disciplina de inglês, os cursos especializados em Estudos de Mídia também estavam se tornando mais populares. De certa forma, esse foi o momento em que a Educação Midiática se institucionalizou.

Levaria muito tempo para explicar o que aconteceu nos anos que se passaram. Mas agora, após dez anos de governos liderados por conservadores, o debate sobre a educação passou a ser dominado por uma espécie de populismo retrógrado, que realmente tem pouco lugar para a Educação Midiática. Os políticos, muitas vezes, falam sobre os perigos das "notícias falsas" e assim por diante, mas eles realmente não estão interessados em alunos aprendendo a criticar a mídia. Há uma visão dominante de que, se a mídia é lixo, então a Educação Midiática também é, obviamente, lixo.

Portanto, nos últimos anos, a mídia foi efetivamente excluída do currículo de inglês (ou seja, língua materna e literatura). Professores dessa disciplina foram informados de que "textos digitais" não são permitidos, o que, se pensamos por um momento, é simplesmente loucura. $\mathrm{O}$ assunto especializado em Estudos de Mídia também está sob ataque, embora haja sobrevivido, conquanto não da forma que muitos de nós desejaríamos. Tenho escrito bastante no meu blog sobre os detalhes terríveis desse processo.

É importante estar ciente de que Estudos de Mídia é um curso opcional que os alunos podem seguir, geralmente, nos quatro anos do ensino médio (e não em todas as escolas). Nos últimos anos, o governo vem priorizando as disciplinas tradicionais, especialmente as STEM (ciências e matemática), e os Estudos de Mídia, como outras disciplinas de humanidades, ciências sociais e artes, têm sido constantemente marginalizados. Menos de $10 \%$ dos alunos 
fazem curso especializado em Estudos de Mídia, e o número de alunos que o escolhem está caindo. O Estudos de Mídia foi vítima de políticas educacionais neoconservadoras, embora de forma alguma não esteja sozinho nisso.

Então, em resposta à pergunta, eu diria que o modelo de "conceitos-chave" ainda é muito a abordagem de consenso entre os professores de Estudos de Mídia. Na minha opinião, é uma perspectiva coerente e abrangente, o que permite levar em conta os novos desenvolvimentos no ambiente mais amplo da mídia: então, embora tenha sido desenvolvido na década de 1980, foi fácil aplicá-lo às mídias sociais, por exemplo.

No entanto, o status dos Estudos de Mídia como assunto especializado - e da Educação Midiática como campo mais amplo - não parece bom. Os argumentos mais amplos que venho apresentando aqui estão totalmente fora de sintonia com a direção em curso da política educacional. Posso continuar argumentando que é imperioso preparar os jovens para um mundo saturado pela mídia. Considero que necessitamos de uma abordagem mais coerente e integrada para ensinar sobre cultura e comunicação. De forma pragmática, é possível defender a ideia de que a Educação Midiática pode colaborar na resolução de inúmeros problemas de desinformação, ou segurança on-line, ou cyberbullying, ou qualquer que seja o último tópico de preocupação. Mas, no momento, duvido muito que nossos formuladores de políticas educacionais estejam ouvindo.

CEEE: Há um debate relevante no campo científico sobre o possível desaparecimento das disciplinas curriculares. Alguns autores apostam em abordagens interdisciplinares para lidar com as características multifacetadas dos fenômenos contemporâneos. Nesse sentido, o senhor vê a necessidade de a escola ter educadores especializados em Educação Midiática? E como a Educação Midiática pode ser tratada nos cursos superiores que oferecem formação básica de professores?

DB: Conforme disse anteriormente, a interdisciplinaridade não está em pauta na Grã-Bretanha! Ao contrário, estamos retrocedendo para um currículo muito tradicional centrado em disciplinas mais próximas do ofertado no século XIX do que no XXI. Obviamente, eu veria a mídia (ou melhor, a cultura e a comunicação) como um ótimo exemplo desses fenômenos contemporâneos complexos, que definitivamente precisam ser explorados de muitos ângulos diferentes, usando uma variedade de conceitos e métodos distintos. Mas, infelizmente, não é essa a direção que estamos tomando.

Muitas vezes me perguntam se precisamos de professores especializados em mídia ou se a Educação Midiática deve ser responsabilidade de todos os professores. Minha resposta é que precisamos de ambos. Necessitamos da Educação Midiática como disciplina especializada (isto é, Estudos de Mídia) no ensino médio, mas também precisamos que a Educação Midiática seja uma dimensão de outras disciplinas, desde os primeiros anos. Na década de 1980, muitos educadores de mídia defendiam com bastante veemência "a mídia 
transversalmente em todo o currículo", a ideia de que, assim como todos os professores são professores de língua, todos os professores também deveriam ser professores de mídia.

Existem duas razões principais para isso. A primeira se relaciona ao meu ponto anterior sobre o conhecimento dos alunos fora da escola: por exemplo, quando você está ensinando história ou geografia, ou mesmo ciências, muito do conhecimento que os alunos trazem para a sala de aula será derivado da mídia. É bem possível que muito do que eles pensam saber esteja errado, mas um bom ensino implica se envolver, também, com o que os alunos já sabem.

A segunda razão para essa abordagem transcurricular é que, na prática, todos os professores usam mídias em seu ensino: eles utilizam programas de TV, livros, software de computador e assim por diante. E, como já esclareci, eles precisam fazer perguntas críticas sobre essas mídias, em vez de usá-las como ferramentas instrumentais ou fontes inquestionáveis de informação.

"Mídia transversalmente em todo o currículo" é, talvez, uma espécie de ideal. O que descobrimos na década de 1980 foi que a lealdade dos professores às disciplinas ainda era muito forte. "A linguagem transversalmente em todo o currículo" representou um movimento poderoso: muitas escolas foram obrigadas a desenvolver e implementar políticas nessa área. Mas, na prática, algo que era visto como responsabilidade de todos rapidamente se tornou responsabilidade de ninguém. Os professores falavam da ideia da boca para fora, mas, no final, eram os professores de inglês que estavam realmente fazendo o trabalho. E, claro, os professores são constantemente instados a assumir novas responsabilidades, sendo compreensível que eles frequentemente resistam. Se você realmente deseja que essa interdisciplinaridade aconteça nas escolas, é preciso de muito mais tempo, treinamento e suporte que, muitas vezes, estão disponíveis.

Assim, minha resposta aqui é "ambos/e", não "ou/ou"'. Se quisermos ter uma abordagem sistemática e coerente para o ensino de mídias, e se pretendermos que isso aconteça transversalmente em todo o currículo, ainda precisamos ter professores especializados - que, além de tudo, podem ajudar a treinar seus colegas e apoiar a inovação onde ela está acontecendo.

Isso leva à segunda parte da pergunta. Se esperamos que todos os professores se envolvam com a Educação Midiática, é claro que precisamos treiná-los para isso. Mas, no Reino Unido, e suspeito que também no Brasil, há poucas oportunidades de fazer isso na formação básica de professores. Novamente, muitas vezes, há pressão para assumir a responsabilidade por novos tópicos e questões: coisas são apenas adicionadas ao currículo de formação de professores e parece que nada é retirado! E, claro, você também precisa de instrutores, de acadêmicos, com a experiência relevante para ministrar os cursos. Portanto é fácil saber por que o progresso pode ser bastante lento.

Pessoalmente, acho que os educadores especializados em mídia requisitam

3. Optamos por traduzir desta forma a expressão "both/and" not "either/or". muito treinamento. Você não permitiria que um professor ensinasse história se ele nunca tivesse estudado o assunto. $\mathrm{O}$ mesmo se aplica aqui. Os professores de mídia precisam saber muito sobre toda uma gama de diferentes formas 
de mídias, indústrias midiáticas, teorias acadêmicas e métodos de análise dos meios. E manterem-se atualizados sobre os desenvolvimentos em andamento no mundo das mídias, sobretudo aquelas com as quais os alunos estão envolvidos. Isso requer treinamento inicial aprofundado, bem como formação profissional continuada. Se realmente quisermos levar isso a sério, devemos fazer mais do que apenas elogiar a ideia da boca para fora.

CE'E: Em seu livro The media education manifesto, o senhor é crítico em relação à ideia de que a mídia digital oferece uma forma de "empoderamento", inclusive no contexto escolar. $O$ senhor poderia explicar como vê o papel da Educação Midiática em face do capitalismo digital e os desafios colocados por algoritmos, notícias falsas e a extração de dados pessoais nas redes sociais? Com o crescimento de plataformas como Google, Facebook, Amazon e outras, que papel a Educação Midiática desempenha na promoção de uma cidadania consciente e crítica?

DB: Nos últimos anos, houve uma mudança significativa no teor geral do debate sobre mídia digital. No início, as pessoas falavam entusiasticamente sobre as maravilhas da tecnologia; mas agora tudo o que ouvimos são histórias de terror sobre seus efeitos nocivos. Historicamente, podemos ver mudanças semelhantes em mídias mais antigas, como televisão e cinema. Quando a tecnologia surge, parece ser uma promessa fantástica, no entanto, muito rapidamente, somos informados de que isso está nos levando para o inferno.

No caso da internet, há uma história interessante, que está documentada no livro Da contracultura à cibercultura ${ }^{4}$, de Fred Turner. $\mathrm{O}$ autor mostra como as primeiras ideias sobre a internet surgiram da contracultura hippie do início dos anos 1970. Esses pioneiros viam a internet como uma força para a criatividade, o aprendizado e a democracia participativa: ela levaria poder às pessoas. $\mathrm{O}$ surgimento da "Web 2.0" na virada do século trouxe um entusiasmo renovado por esses tipos de ideias utópicas. No entanto, desde aquela época, a internet e as mídias sociais se tornaram meios de vigilância e marketing comercial em uma escala sem precedentes.

O mesmo é verdade na educação. Os primeiros defensores da tecnologia digital nos disseram que ela democratizaria a sala de aula e levaria a uma nova era de aprendizagem criativa centrada no aluno. Também aqui a realidade tem sido muito diferente: a tecnologia ganhou força de vigilância e um meio de estender a privatização corporativa da educação pública. A libertação que nos foi prometida parece cada vez mais distante.

$\mathrm{Na}$ minha opinião, tanto as visões positivas quanto as negativas sofrem de uma espécie de determinismo tecnológico. Eles atribuem um poder arrogante à tecnologia, independentemente de como e por que ela é usada. A tecnologia não vai nos libertar, apesar do que os profissionais de marketing afirmam, mas também não nos escravizará, necessariamente, a menos que o permitamos. Infelizmente, a tecnologia está cada vez mais sendo usada na educação como um meio de exercer poder político e econômico - de controlar professores e

4. No original, From counterculture to cyberculture, publicado pela University of Chicago Press, em 2008. 
alunos, de coletar dados e de transformar a educação em uma forma de ganhar dinheiro. Todos nós precisamos resistir a isso.

Atualmente, grande parte da discussão sobre os jovens e a mídia digital tende a se concentrar na questão da segurança - pornografia e pedófilos, privacidade, discurso de ódio, cyberbullying e assim por diante. A internet é vista como a principal causa de vício, narcisismo e problemas de saúde mental. E o professor é posicionado aqui como uma espécie de salvador ou protetor moral. No entanto os educadores de mídia sabem por experiência própria que essa postura protecionista raramente é muito eficaz: os alunos costumam vê-la como paternalista e moralista, e resistem a ela.

Em meu Manifesto, argumento que necessitamos ter uma visão mais ampla. Devemos nos concentrar não nos sintomas desses problemas, mas nas causas mais fundamentais. Professores e alunos precisam entender o sistema mais amplo do "capitalismo digital" (ou o que alguns chamam de "capitalismo de vigilância" ou "capitalismo de plataforma”) — e então eles estarão em condições de fazer, por si mesmos, escolhas conscientes.

Isso não é fácil. Estamos lidando com tecnologia onipresente e cada vez mais incorporada em nosso dia a dia. No entanto várias das suas maneiras de funcionamento são invisíveis para nós: por exemplo, muitos não entendemos como funcionam os algoritmos e os sistemas de pesquisa e recomendação. Não entendemos as dimensões econômicas da internet e como os dados são comprados e vendidos. Isso a torna uma forma de poder mais complexa e generalizada, por exemplo, em comparação com a mídia mais antiga, como jornais ou televisão: imaginamos que o estamos controlando e que estamos recebendo um serviço de graça, mas não é isso que está acontecendo.

Contudo acho que podemos usar os "conceitos-chave" da Educação Midiática para nos ajudar a questionar isso e explorar como funciona. Tal como acontece com a mídia mais antiga, esta abordagem ajudará os alunos a analisar e refletir sobre como eles usam as tecnologias em seus cotidianos, permitirá que questionem a confiabilidade e credibilidade do material que veem e os encorajará a compreender as forças sociais, políticas e econômicas mais amplas que estão em jogo. As novas mídias apresentam novos desafios, mas também são uma parte inextricável da cultura da mídia mais ampla, que inclui também a "velha" mídia. Algumas pessoas estão pedindo a inclusão de um novo assunto, a "alfabetização digital", mas não faz sentido separar a mídia digital de outros tipos de mídia ou da cultura e das comunicações de forma mais ampla.

Em última análise, eu concordaria que esta é uma questão de cidadania consciente e crítica, como dito na pergunta; embora eu também tema que cidadania seja um termo bastante amplo. Nestes tempos neoliberais, parece particularmente importante afirmar que não somos apenas consumidores individuais, mas também cidadãos na esfera pública. "Cidadania" é uma ideia normativa que implica um sistema de democracia participativa, em que as pessoas têm voz e ação. Temo que este seja um longo caminho desde a política populista que agora domina especialmente no Reino Unido e no Brasil. 
A Educação Midiática pode ser uma maneira de promover esse tipo de cidadania, mas não acho que seja suficiente por si só. Cabe-nos a tarefa de tentar criar usuários críticos e "alfabetizados em mídia", mas também se impõe uma reforma fundamental do nosso sistema de mídia. As grandes empresas que atuam na área, conforme mencionado na pergunta, precisam ser responsabilizadas por suas ações; elas devem ser muito mais transparentes e responsáveis e não podem ter a permissão de operar quase como monopólios. No mínimo, cabe a elas a obrigação de pagar seus impostos! Tudo isso requer regulamentação por parte do governo, conquanto muitos deles não pareçam estar dispostos a exercer a obrigação fiscalizatória.

Como disse outro escritor de manifesto, não basta interpretar o mundo: também temos que mudá-lo. A Educação Midiática não deve apenas nos permitir lidar com esse novo mundo digital: cabe a ela nos encorajar a imaginar e exigir algo diferente!

Tradução do inglês por Douglas Calixto e Tatiana Luz-Carvalho

Revisão da tradução: Evelyn Soares Raposo. 